F. Pichler R. Moreno Díaz (Eds.)

\title{
Computer Aided Systems Theory - EUROCAST '91
}

A Selection of Papers from the

Second International Workshop on

Computer Aided Systems Theory

Krems, Austria, April 15-19, 1991

Proceedings

Springer-Verlag

Berlin Heidelberg New York

London Paris Tokyo

Hong Kong Barcelona

Budapest 
Series Editors

Gerhard Goos

Universität Karlsruhe

Juris Hartmanis

Postfach 6980

Vincenz-Priessnitz-Straße 1

Cornell University

W-7500 Karlsruhe, FRG

Department of Computer Science

5149 Upson Hall

Ithaca, NY 14853, USA

\section{Volume Editors}

Franz Pichler

Institute of Systems Science, Johannes Kepler University

Altenbergerstr. 69, A-4040 Linz, Austria

Roberto Moreno Díaz

Dept. of Computer Science and Systems, Univ. of Las Palmas de Gran Canaria

P. O. Box 550, 35080 Las Palmas, Spain

CR Subject Classification (1991): H.1, J.6, I.6, I.2, J.7, J.3

ISBN 3-540-55354-1 Springer-Verlag Berlin Heidelberg New York ISBN 0-387-55354-1 Springer-Verlag New York Berlin Heidelberg

This work is subject to copyright. All rights are reserved, whether the whole or part of the material is concerned, specifically the rights of translation, reprinting, re-use of illustrations, recitation, broadcasting, reproduction on microfilms or in any other way, and storage in data banks. Duplication of this publication or parts thereof is permitted only under the provisions of the German Copyright Law of September 9, 1965, in its current version, and permission for use must always be obtained from Springer-Verlag. Violations are liable for prosecution under the German Copyright Law.

(C) Springer-Verlag Berlin Heidelberg 1992

Printed in Germany

Typesetting: Camera ready by author

Printing and binding: Druckhaus Beltz, Hemsbach/Bergstr.

45/3140-543210 - Printed on acid-free paper 


\section{Preface}

This volume contains a selection of papers presented at the second European workshop EUROCAST'91 held in Krems, Austria, in April 1991. It should give an overview on the current state of CAST research and its relation to $C A D$ applications in the engineering fields. Publishing in the Lecture Notes in Computer Science is motivated by the following two reasons:

(1) CAST research requires the application of the most advanced information processing technology in software and hardware for the implementation of CAST method base systems

(2) the specific engineering disciplines (especially the field of information and control engineering) have the opportunity to present the state of the art in modelling tools to computer scientists

EUROCAST'91 proved that CAST research is still in its beginning state of development. However we can see by the results which were achieved in the workshop that progress towards a common understanding of the task is continuing.

EUROCAST ' 91 was organized by the Wissenschaftliche Landesakademie Krems, Austria, in cooperation with the Johannes Kepler University Linz, Austria, and the Universidad de Las Palmas de Gran Canaria, Canary Islands, Spain. Professor Peter Kopacek, Conference-Chairman of the workshop, and his team deserve many thanks for the organizational work. The organizers are grateful for the co-sponsorship of the International Federation of Systems Research (IFSR), the International Federation of Automatic Control (IFAC), and the Technical Committee on Systems Engineering (SECOM).

The editors of this volume would once more like to thank our mentor in CAST research Professor Heinz Schwärtzel, Siemens Corporation Munich, and current president of the German Society for Computer Science, for his encouragement and advice. Many thanks also to Professor Gerhard Goos, University of Karlsruhe and Editor-in-Chief of the Lecture Notes in Computer Science, for his understanding and acceptance of our publication. A final word of thanks goes to the Springer-Verlag staff in Heidelberg for their help in publishing this volume.

February 1992

Franz Pichler, Roberto Moreno-Díaz 